\title{
Fractionation and Characterization of Fractions with High Antioxidative Activity from the Gelatin Hydrolysates of Korean Rockfish Sebastes schlegelii Skin
}

\author{
Hyung Jun Kim ${ }^{1}$, Kwon Hyun Park ${ }^{2}$, Jun Ho Shin ${ }^{2}$, Ji Sun Lee ${ }^{2}$, Min Soo Heu ${ }^{3}$, Dong Ho Lee ${ }^{1}$ and Jin-Soo Kim ${ }^{2 *}$ \\ ${ }^{1}$ Children's Dietary Life Safety Division, Korea Food \& Drug Administration, Cheongwon 363-951, Korea \\ ${ }^{2}$ Department of Seafood Science and Technology/Institute of Marine Industry, Gyeongsang National University, Tongyeong 650-160, Korea \\ ${ }^{3}$ Department of Food Science and Nutrition/Institute of Marine Industry, Gyeongsang National University, Jinju 660-701, Korea
}

\begin{abstract}
The purpose of this study was to obtain a fraction with high antioxidative activity from second rockfish gelatin hydrolysates (SRSGHs), which were hydrolyzed with Alcalase and Flavourzyme through ultrafiltration membranes with serial digestions for 1 and 2 $\mathrm{h}$, respectively, and to investigate the feasibility of this fraction as a potential functional food ingredient. Among various fractions that were ultrafiltered from the SRSGH with four types of membrane $(1,5,10$, and $30 \mathrm{kDa})$, the SRSGH-III fraction, which permeated the $10 \mathrm{kDa}$ membrane but not the $5 \mathrm{kDa}$ membrane, showed the highest antioxidant activity (protection factor=5.13) and angiotensin-I-converting enzyme-inhibiting activity $\left(\mathrm{IC}_{50}=0.82 \mathrm{mg} / \mathrm{mL}\right)$. These results suggest that the SRSGH-III fraction from the SRSGH can be used as a functional food ingredient. However, further studies examining its antioxidant activity in vivo as well as the different antioxidant mechanisms are needed.
\end{abstract}

Key words: Rockfish, Rockfish gelatin, Fish gelatin hydrolysate, Fish by-product, Ultrafiltration

\section{Introduction}

Korean rockfish Sebastes hubbsi is one of the primary aquaculture species in Korea, with an estimated yield of 20,918 M/T in 2010 (Fishery Production Survey, 2011). These large yields provide a unique opportunity for gelatin extractions from rockfish skin, which is generated in sizeable quantities $(\sim 3.4 \%$ of a whole fish) as a byproduct in sliced raw fish production (Kim et al., 2011). Because of the low rheological properties of fish gelatin (Kim and Park, 2004) and its conversion into biologically active peptides by enzymatic hydrolysis, the skin of many fish species has been investigated as a potential source of natural antioxidants against lipid peroxidation and inhibitors of angiotensin I converting enzyme (ACE) (Byun and Kim, 2001; Kim et al., 2001a). The intact form of the gelatin contains many bioactive proteins due to the presence of bio- logically active peptide sequences in their primary structures. Numerous methods have been used to release bioactive peptide fractions from native proteins; proteolytic digestion and fractionation through ultrafiltration (UF) membranes with different molecular weight cut-offs (MWCOs) is one of the most common methods (Kim et al., 1994, 2001b; Jeon et al., 2000). Fractionation through UF membranes has several advantages, such as the mass-production capability and the enhancement of some functional properties in comparison with the original hydrolysate. It also involves a simpler separation process and lower production cost than chromatographic processing (Jeon et al., 2000). Thus, the ability to produce functional gelatin hydrolysates from rockfish skin gelatin should be examined, and the resulting fractions should be tested for high antioxida-
Open Access http://dx.doi.org/10.5657/FAS.2011.0168

This is an Open Access article distributed under the terms of the Creative Commons Attribution Non-Commercial License (http://creativecommons. org/licenses/by-nc/3.0/) which permits unrestricted non-commercial use, distribution, and reproduction in any medium, provided the original work is properly cited. pISSN: 2234-1749 eISSN: 2234-1757
Received 27 May 2011; $\quad$ Revised 27 July 2011;

Accepted 9 August 2011

*Corresponding Author

E-mail: jinsukim@gnu.ac.kr 
tive and/or ACE-inhibiting activities by enzymatic hydrolysis and fractionation using the UF system.

Although several studies have examined the fractionation and isolation of functional peptides from hydrolysates of fish skin (Kim et al., 2001a, 2001b; Mendis et al., 2005), with the exception of Kim et al. (2011), no research has evaluated the feasibility of using rockfish skin gelatin as a source of functional gelatin hydrolysates. The objective of this study was to obtain a fraction with high antioxidant activity from rockfish skin gelatin hydrolysates by fractionation through UF membranes.

\section{Materials and Methods}

\section{Materials}

Korean rockfish skin, a byproduct of sliced raw fish production, was obtained from the Geoje National Federation Fisheries Cooperatives (Geoje, Korea) in December 2007. The skin was mechanically separated and residual muscle and scales were removed manually. After washing thoroughly with running tap water, the skin was placed in polyethylene bags and stored at $-25^{\circ} \mathrm{C}$ until use.

Alcalase (2.4 LFG, from Bacillus licheniformis; optimal temperature, $55-70^{\circ} \mathrm{C}$; optimal $\left.\mathrm{pH}, 6.5-8.5\right)$ and Flavourzyme (500 MG, from Aspergillus oryzae; optimal temperature, $50^{\circ} \mathrm{C}$; optimal $\mathrm{pH}, 7.0$ ) were purchased from Novo Co. (Novo Nordisk, Bagsvaerd, Denmark).

The UF membrane bioreactor system (Amicon 8200, Millipore Co., MA, USA) and membranes (1, 5, 10, and $30 \mathrm{kDa})$ for fractionation of the second rockfish skin gelatin hydrolysates (SRSGHs) were purchased from Millipore Co. (Bedford, MA, USA).

All radical testing chemicals, including 1,1-diphenyl2-picrylhydrazyl (DPPH), 5,5-dimethyl-1-pyrroline N-oxide (DMPO), 2,2'-azobis (2-amidinopropane) hydrochloride (AAPH), and $\alpha$-(4-pyridyl-1-oxide)-N-tert-butylnitrone (4POBN), were purchased from Sigma-Aldrich Co. (St. Louis, MO, USA).

All other reagents used in this study were of analytical grade and were used without any further purification.

\section{Preparation and fractionation of the second gela- tin hydrolysates}

The Korean rockfish skin gelatin and its first gelatin hydrolysate (FRSGH), which was used for the SRSGH and its fraction, were prepared as described by Kim et al. (2010). The SRSGH was prepared by further incubating the FRSGH, which included gelatin hydrolysate digested with Alcalase for $2 \mathrm{~h}$ and with Flavourzyme for $1 \mathrm{~h}$, at a protein-to-enzyme ratio of $100: 2(\mathrm{w} / \mathrm{w})$ at $50^{\circ} \mathrm{C}$.

For the fractionation of permeates with high antioxidative activity, the SRSGH was sequentially fractionated based on molecular weight using four types of UF membranes with MWCOs of 30, 10, 5, and $1 \mathrm{kDa}$. The fractions were defined according to molecular size and the resultant supernatant and permeates as follows: SRSGH-I, supernatant that did not permeate the $30 \mathrm{kDa}$ membrane; SRSGH-II, permeate that permeated the $30 \mathrm{kDa}$ membrane but not the $10 \mathrm{kDa}$ membrane; SRSGH-III, permeate that permeated the $10 \mathrm{kDa}$ membrane but not the $5 \mathrm{kDa}$ membrane; SRSGH-IV, permeate that permeated the $5 \mathrm{kDa}$ membrane but not the $1 \mathrm{kDa}$ membrane; and SRSGH-V, permeate that permeated the $1 \mathrm{kDa}$ membrane. The fraction (SRSGH-I) and permeates (SRSGH-II to V) of SRSGH were lyophilized for 5 days with a freeze-drier (FDU540; Eyela, Tokyo, Japan).

\section{Induction period and protection factor}

The induction periods (IPs) of SRSGH and SRSGH-I to V were determined at $120^{\circ} \mathrm{C}$ using an automated Rancimat apparatus (Model 743; Metrohm, Herisau, Switzerland) as described by Frega et al. (1999). The glassware was thoroughly cleaned and dried prior to each determination. Soybean oil $(2.5 \mathrm{~g})$ was weighed directly in the reaction vessels and mixed vigorously for $30 \mathrm{~s}$. The SRSGH or SRSGH-I to V $(0.5 \mathrm{~g})$ and Tween-80 (0.2 g) were added to the soybean oil and mixed with a vortex for $30 \mathrm{~s}$. The air-flow rate through the sample was adjusted to $20 \mathrm{~L} / \mathrm{h}$. The volatile reaction products released during oxidation of soybean oil were collected in 60 $\mathrm{mL}$ of distilled water in the collection vessel. The change in the conductivity was plotted automatically until the endpoint was reached. With each soybean oil oxidation, a control test (without hydrolysates or permeates) was included and subjected to the same experimental conditions. The antioxidative activity was measured in duplicate for each sample and the IP (in hours) was recorded. The relative antioxidative activity of SRSGH and SRSGH-I to V was expressed as the protection factor (PF), defined as follows:

$$
\mathrm{PF}=\frac{\text { IP of soybean oil with hydrolysate or permeate }}{\text { IP of soybean oil with distilled water (control) }}
$$

\section{Radical scavenging activity}

The DPPH free radical scavenging activity of SRSGH and SRSGH-III was measured as described by Nanjo et al. (1996). A $60 \mu \mathrm{L}$ peptide solution (or ethanol as control) was added to $60 \mu \mathrm{L}$ of DPPH $(60 \mu \mathrm{M})$ in ethanol solution. After mixing vigorously for $10 \mathrm{~s}$, the solution was transferred into A $100 \mu \mathrm{L}$ quartz capillary tube, and the scavenging activity of peptide on DPPH free radical was measured using a JES-FA electron spin resonance (ESR) spectrophotometer (JEOL Ltd., Tokyo, Japan). The spin adduct was measured on an ESR spectrophotometer exactly 2 min later. Experimental conditions were as follows: magnetic field, $336.5 \pm 5 \mathrm{mT}$; power, $5 \mathrm{~mW}$; modula- 
tion frequency, $9.41 \mathrm{GHz}$; amplitude, $1 \times 1,000$; sweep time, $30 \mathrm{~s}$.

The hydroxyl radical scavenging activity was measured with a JES-FA ESR spectrophotometer (JEOL Ltd. Tokyo, Japan) using the method of Rosen and Rauckman (1980). Hydroxyl radicals were generated by the Fenton reaction $\left(\mathrm{Fe}^{2+}+\mathrm{H}_{2} \mathrm{O} \rightarrow \mathrm{OH}+\mathrm{OH}^{-}\right)$, a well-known and -defined generator of ${ }^{\circ} \mathrm{OH}$, and the radicals produced were reacted rapidly with a nitron spin trap with DMPO. The reaction mixture contained $20 \mu \mathrm{L}$ of sample, $20 \mu \mathrm{L}$ of $0.3 \mathrm{M}$ DMPO, $20 \mu \mathrm{L}$ of $10 \mathrm{mM}$ $\mathrm{FeSO}_{4} \cdot 7 \mathrm{H}_{2} \mathrm{O}$, and $20 \mu \mathrm{L}$ of $10 \mathrm{mM} \mathrm{H}_{2} \mathrm{O}_{2}$. The resultant DM$\mathrm{PO}-\mathrm{OH}$ adducts were investigated and the ESR spectrum was recorded after $2.5 \mathrm{~min}$. The measurement conditions were as follows: central field, $3475 \mathrm{G}$; modulation width, $0.2 \mathrm{mT}$; amplitude, $100 \mathrm{mT}$; microwave power, $1 \mathrm{~mW}$; sweep width, 10 $\mathrm{mT}$; and temperature, $298 \mathrm{~K}$.

Superoxide radicals were generated by ultraviolet (UV) irradiation of a riboflavin/EDTA solution and their scavenging abilities were investigated using the method of Zhao et al. (1989). The reaction mixture containing $0.8 \mathrm{mM}$ riboflavin, $1.6 \mathrm{mM}$ EDTA, $800 \mathrm{mM}$ DMPO, and samples was irradiated for 1 min under a UV lamp at $365 \mathrm{~nm}$. The mixture was transferred to a $100 \mu \mathrm{L}$ quartz capillary tube of the ESR spectrometer for measurements. Experimental conditions were as follows: magnetic field, $336.5 \pm 5 \mathrm{mT}$; power, $10 \mathrm{mV}$; modulation frequency, $9.41 \mathrm{GHz}$; amplitude, $1 \times 1,000$; sweep time, $1 \mathrm{~min}$.

Alkyl radicals were generated by AAPH and their scavenging activities were investigated following the method of Hiramoto et al. (1993). The reaction mixture containing $20 \mu \mathrm{L}$ of distilled water, $20 \mu \mathrm{L}$ of extract, $20 \mu \mathrm{L}$ of $40 \mathrm{mM} \mathrm{AAPH}$, and $20 \mu \mathrm{L}$ of $40 \mathrm{mM} 4-\mathrm{POBN}$ was incubated at $37^{\circ} \mathrm{C}$ for $30 \mathrm{~min}$. The reactants were transferred to a $50 \mu \mathrm{L}$ glass capillary tube and fitted into the ESR spectrophotometer. The measurement conditions were as follows: central field, $3475 \mathrm{G}$; modulation width, $0.2 \mathrm{mT}$; amplitude, 500; microwave power, $8 \mathrm{~mW}$; sweep width, $10 \mathrm{mT}$; and temperature, $298 \mathrm{~K}$.

\section{ACE-inhibiting activity}

The ACE-inhibitory activities of SRSGH and SRSGH-III were assayed by measuring the concentration of hippuric acid liberated from hippuryl-His-Leu according to a modification of the method of Horiuchi et al. (1982). For each assay, 15 $\mu \mathrm{L}$ of sample solution with $50 \mu \mathrm{L}$ of ACE (purified enzyme from rabbit lung in solution, $60 \mathrm{mU} / \mathrm{mL}$ ), and $100 \mu \mathrm{L}$ of $0.1 \mathrm{M}$ sodium borate buffer $(\mathrm{pH} 8.3)$ was pre-incubated at $37^{\circ} \mathrm{C}$ for $5 \mathrm{~min}$ and then incubated with $125 \mu \mathrm{L}$ of substrate $(5 \mathrm{mM}$ hippuryl-His-Leu in $0.1 \mathrm{M}$ sodium borate buffer containing $0.6 \mathrm{M}$ $\mathrm{NaCl}, \mathrm{pH} 8.3$ ) at $37^{\circ} \mathrm{C}$ for $30 \mathrm{~min}$. The reaction was stopped by adding $20 \mu \mathrm{L}$ of $10 \%$ trifluoroacetic acid. The hippuric acid concentration was determined using high-performance liquid chromatography (HPLC; HP 1100; Hewlett Packed Co., Palo Alto, CA, USA) with a Zorbax $300 \mathrm{SB} \mathrm{C}_{8}$ column $(4.6 \times 150$ $\mathrm{mm})$. The $\mathrm{IC}_{50}$ value was defined as the concentration of inhibitor required to inhibit $50 \%$ of the ACE-inhibitory activities.

\section{Molecular weight profile}

Aliquots of $20 \mu \mathrm{L}$ of SRSGH and SRSGH-III were injected onto a Shodex protein KW-804 column (i.d. 8×300 mm; Showa Denko, Tokyo, Japan), equilibrated with $50 \mathrm{mM}$ sodium phosphate buffer (pH 6.0) containing $100 \mathrm{mM} \mathrm{NaCl}$, and analyzed using HPLC (LC-10AT vp; Shimadzu, Kyoto, Japan) at a flow rate of $1 \mathrm{~mL} / \mathrm{min}$. The elution profile of the protein was monitored using a UV-Vis detector (SPD-10AV vp; Shimadzu) at $215 \mathrm{~nm}$. The molecular weights of the standard proteins (Sigma-Aldrich Chemical Co., St. Louis, MO, USA) used were as follows: aprotinin (6,500 Da), cytochrome c $(12,400$ $\mathrm{Da})$ carbonic anhydrase $(29,000 \mathrm{Da})$, bovine serum albumin $(66,000 \mathrm{Da})$, and alcohol dehydrogenase (150,000 Da).

\section{Amino acid composition}

The amino acid compositions of SRSGH and SRSGH-III containing antioxidative peptides were determined using an amino acid analyzer (Biochrom. 30; Pharmacia. Biotech, Uppsala, Sweden). The samples $(50 \mathrm{mg}$ ) were hydrolyzed in 6 $\mathrm{N} \mathrm{HCl}$ in evacuated/sealed tubes at $110^{\circ} \mathrm{C}$ for $16 \mathrm{~h}$. The acidtreated sample was evaporated to dryness at $50^{\circ} \mathrm{C}$ in a vacuum evaporator, diluted with sodium citrate buffer $(\mathrm{pH} 2.2)$, and then used as a sample for amino acid analysis.

\section{Results and Discussion}

\section{Protection factor}

The antioxidative activities, expressed as PF, of SRSGH-I to $\mathrm{V}$ are shown in Fig. 1. The antioxidative activity was high-

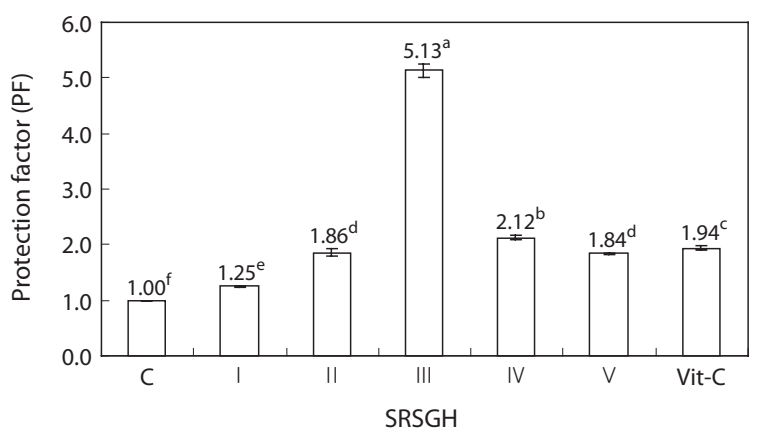

Fig. 1. Antioxidative activities of the supernatant and the permeates from SRSGH through UF membranes. The control is defined where no the supernatant or the permeates is added in the antioxidative activity test. C, distilled water; I , >30 kDa fraction; II, 30 to $10 \mathrm{kDa}$ fraction; III, 10 to $5 \mathrm{kDa}$ fraction; IV 5 to $1 \mathrm{kDa}$ fraction; $\mathrm{V},<1 \mathrm{kDa}$ fraction filtrated by the ultrafiltration membrane; Vit-C, vitamin C; SRSGH, second rockfish gelatin hydrolysates; UF, ultrafiltration; IP, induction periods.

$$
\mathrm{PF}=\frac{\text { IP of soybean oil with hydrolysate or permeate }}{\text { IP of soybean oil with distilled water (control) }}
$$


est in SRSGH-III $(\mathrm{PF}=5.13)$, followed by the SRSGH-IV fraction $(\mathrm{PF}=2.12)$. The antioxidative activities of the other fractions ranged from 1.25 to 1.86 . When compared with the antioxidant activity of $20 \mathrm{mM}$ ascorbic acid, those of SRSGHIII and -IV were higher, while those of SRSGH-I, -II, and -V were lower. These results suggest that SRSGH-III contained peptides with higher antioxidant activities. Mendis et al. (2005) reported that antioxidant peptides isolated from hoki skin gelatin hydrolysate were composed of His-Gly-Pro-LeuGly-Pro-Leu. Kim et al. (2001b) reported that the peptides (P1 and P2) fractionated and isolated from gelatin hydrolysate of Alaska pollock skin were composed of 13 and 16 amino acid residues, respectively, and that both peptides contained glycine residues at the $\mathrm{C}$-terminus and repeating glycine-prolinehydroxyproline. These reports, as well as our results, suggest that sequential enzymatic hydrolysis of rockfish skin gelatin with Alcalase/Flavourzyme followed by fractionation are suitable methods for obtaining antioxidant peptides.

\section{Radical scavenging activity}

The ability of SRSGH and the SRSGH-III fraction to scavenge DPPH free, hydroxyl, superoxide, and alkyl radicals was determined using an electron spin trapping technique. The resultant chromatograms, expressed as the ESR signal intensity, and their radical scavenging activity, expressed as a percentage of the ESR signal intensity of control samples, are shown in Figs. 2 and 3, respectively. Treatment with SRSGH-III led to increased scavenging activity and the generation of DPPH radicals by $93.0 \pm 2.2 \%$ at a concentration of $4 \mathrm{mg} / \mathrm{mL}$ compared with the control sample. This antioxidant activity was higher than that of SRSGH $(45.8 \pm 1.0 \%)$, but similar to that of $20 \mathrm{mM}$ ascorbic acid $(95.5 \pm 0.2 \%)$. In the presence of the same concentration of SRSGH-III, the signals of the superoxide anion-DMPO spin adduct generated in the irradiated riboflavin system were suppressed by $73.8 \pm 0.4 \%$, which was higher than observed for SRSGH $(67.8 \pm 1.5 \%)$ but lower than found for 20 $\mathrm{mM}$ ascorbic acid $(77.4 \pm 0.4 \%)$.

The Fenton reaction was utilized to generate hydroxyl radicals, and the typical 1:2:2:1 ESR signal of the DMPO-OH adduct was also suppressed at a relatively high percentage of $95.2 \pm 0.1 \%$ with the same concentration of SRSGH-III. This was similar to that of SRSGH $(94.7 \pm 4.8 \%)$ but higher than that of $20 \mathrm{mM}$ ascorbic acid (93.0 $\pm 0.3 \%)$. These results likely reflect that all organic molecules, including peptides, are highly susceptible to oxidization by extremely reactive hydroxyl radicals (Rajapakse et al., 2005). This higher activity could also be due to a higher chelating ability, which retards the generation of hydroxyl radicals via the Fenton reaction (Rajapakse et al., 2005). Alkyl radicals were generated from AAPH in the presence of 4-POBN (Kong et al., 2009). As shown in Fig. 2 , treatment with SRSGH-III significantly reduced the intensity of the spin adduct of the 4-POBN radical generated from AAPH at a concentration of $4 \mathrm{mg} / \mathrm{mL}$; inhibitory activity was
$73.7 \pm 1.9 \%$ compared with the control, which was higher than that of SRSGH (64.8 $\pm 3.3 \%$ ) but lower than that of $20 \mathrm{mM}$ ascorbic acid $(83.4 \pm 1.5 \%)$, a natural antioxidant.

In comparing our results to an analysis of the ESR spectrum, SRSGH-III exhibited dose-dependent scavenging effects on all four kinds of radicals, but the degree of scavenging differed. Among the four radicals, DPPH and hydroxyl radicals were scavenged most effectively.

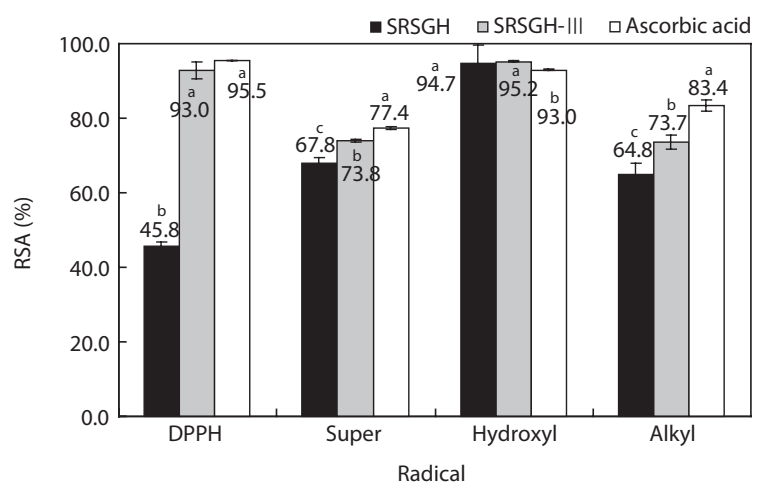

Fig. 2. Radical (DPPH radical, superoxide radical, hydroxyl radical, alkyl radical) scavenging activity (RSA) of SRSGH and SRSGH-III. SRSGH, gelatin hydrolysate by sequential treatment of Alcalase for $1 \mathrm{~h}$ / Flavourzyme $2 \mathrm{~h}$; SRSGH-III, permeates permeated from SRSGH through the $10 \mathrm{kDa}$ membrane but not permeated through the $5 \mathrm{kDa}$ membrane.

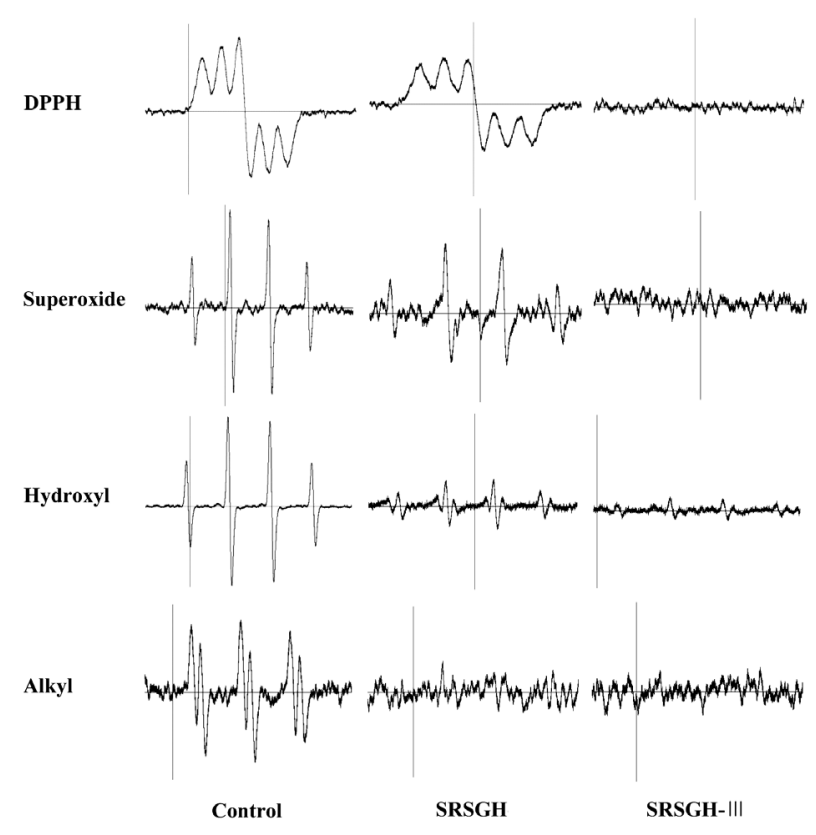

Fig. 3. Radical (DPPH radical, superoxide radical, hydroxyl radical, alkyl radical) scavenging chromatograms of SRSGH and SRSGH-III. SRSGH, gelatin hydrolysate by sequential treatment of Alcalase for $1 \mathrm{~h} /$ Flavourzyme $2 \mathrm{~h}$; SRSGH-III, permeates permeated from SRSGH through the $10 \mathrm{kDa}$ membrane but not permeated through the $5 \mathrm{kDa}$ membrane. 


\section{ACE-inhibiting activity}

The ACE-inhibiting activities, expressed as $\mathrm{IC}_{50}$ values, of SRSGH and the SRSGH-III fraction are shown in Fig. 4. The ACE-inhibiting activity of SRSGH-III was $0.82 \mathrm{mg} / \mathrm{mL}$, which was similar to that of SRSGH $(1.10 \mathrm{mg} / \mathrm{mL})$ but superior to that of FRSGH, as reported by Kim et al. (2011). Jeon et al. (2000) studied the functional properties of the supernatant and permeates from cod frame protein hydrolysates using UF membranes with MWCOs of 30, 10, 5, and $3 \mathrm{kDa}$, and reported that the $10-\mathrm{K}$ and $3-\mathrm{K}$ permeates showed high antioxidative activity and excellent ACE-inhibitory activity, respectively.

These results suggest that the SRSGH-III fraction exhibited the highest antioxidative activity and thus may be used as a food ingredient to improve health and functional properties, such as antioxidative and ACE-inhibiting activities.

\section{Molecular weight profile}

SRSGH and the SRSGH-III fraction were separated using gel chromatography on a Sephadex G-50 (Sigma-Aldrich CO. MA, USA) instrument to analyze the peptide size; results are shown in Fig. 5. Both SRSGH and the SRSGH-III fraction exhibited broad single peaks on the chromatogram. The absorbances were detected in the fractions collected from 19.5-25.5 min for the SRSGH, and from 20.5-25.5 min for the SRSGHIII. This result indicated a decrease in molecular weight according to membrane fractionation (Chang et al., 2007). The chain lengths of the peptides, which depend on the degree of hydrolysis and membrane size, are of particular interest with respect to organoleptic and health/functional characteristics (Gbogouri et al., 2004). As expected, when compared to the SRSGH, the relative proportion in the SRSGH-III decreased at the $29.0 \mathrm{kDa}$ peak. Jeon et al. (2000) reported a similar correlation between the molecular weight of the fraction obtained with UF membranes and the specificity of the antioxidative activity.

\section{Amino acid composition}

The amino acid compositions, expressed as g/100 g amino acids, of SRSGH and SRSGH-III are shown in Table 1. Both SRSGH and SRSGH-III were rich in hydroxyproline $(8.8 \%$ and $11.8 \%$, respectively), glycine $(25.9 \%$ and $18.0 \%$, respectively), proline (10.8\% and $11.7 \%$, respectively), alanine (9.1\% and $9.4 \%$, respectively), glutamic acid $(9.1 \%$ and $9.4 \%$, respectively) and arginine $(9.2 \%$ and $12.8 \%$, respectively), but poor in threonine ( $2.5 \%$ and not detected, respectively), cystine (not detected in either product), valine $(2.1 \%$ in both products), methionine ( $1.6 \%$ and $1.5 \%$, respectively), isoleucine $(0.8 \%$ in both products), leucine $(1.9 \%$ and $2.0 \%$, respectively), tyrosine $(0.4 \%$ and $0.5 \%$, respectively), hydroxylysine $(0.9 \%$ and $1.2 \%$, respectively), and histidine $(0.9 \%$ and $1.2 \%$, respectively). Thus, differences in the amino acid composi-

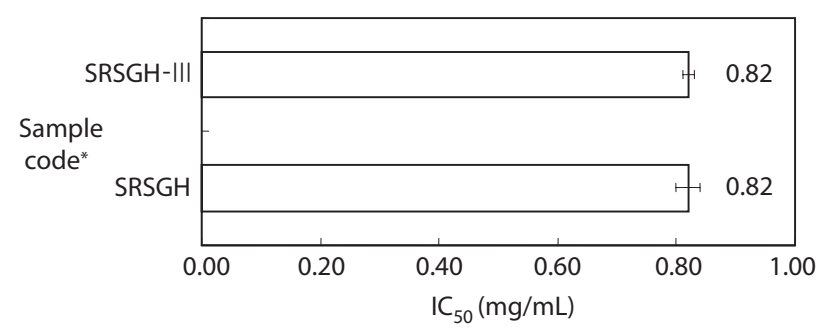

Fig. 4. Angiotensin I converting enzyme (ACE) ${ }^{* *}$ inhibitory activities $\left(\mathrm{IC}_{50}\right)^{{ }^{*+* *}}$ of SRSGH and SRSGH-III. "SRSGH, rockfish skin gelatin hydrolysate digested sequentially with Alcalase for $1.0 \mathrm{~h} /$ Flavourzyme for $2.0 \mathrm{~h}$; SRS$\mathrm{GH}-\mathrm{III}$, permeates permeated from SRSGH through the $10 \mathrm{kDa}$ membrane but not permeated through the $5 \mathrm{kDa}$ membrane, "ACE inhibition was determined with $15 \mathrm{uL}$ of each hydrolysate, ${ }^{* * * \neq} I C_{50}$ value was defined as the concentration of inhibitor required to inhibit $50 \%$ of the ACE inhibitory activity.

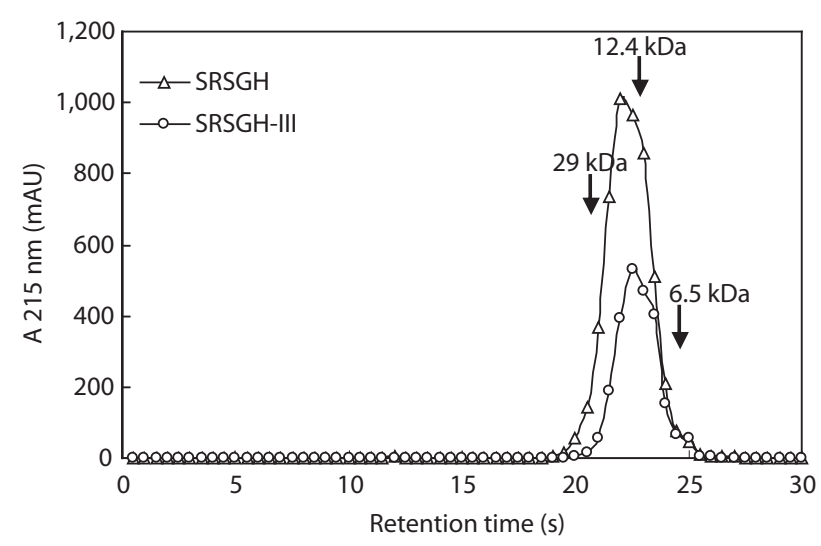

Fig. 5. Molecular weight distribution profiles of rockfish skin gelatin and its first and second gelatin hydrolysates. SRSGH, rockfish skin gelatin hydrolysate digested sequentially with Alcalse for $1.0 \mathrm{~h} /$ Flavourzyme for $2.0 \mathrm{~h}$; SRSGH-III, permeates permeated from SRSGH through the $10 \mathrm{kDa}$ membrane but not permeated through the $5 \mathrm{kDa}$ membrane. Standards: alcohol dehydrogenase $(150 \mathrm{kDa})$, bovine serum albumin $(66 \mathrm{kDa})$, carbonic anhydrase (29 kDa), cytochrome C (12.4 kDa), aprotinin (6.5 kDa).

tions of SRSGH and SRSGH-III were found for hydroxyproline, threonine, glycine, and arginine.

The results of this study demonstrate that the SRSGH-III fraction showed relatively high antioxidant and ACE-inhibiting activities. Consumer demand for natural functional foods has increased, and the SRSGH-III fraction reported herein may be used as a functional food ingredient for its antioxidant properties. However, additional studies of the antioxidant activities of SRSGH-III in vivo and its antioxidant mechanisms are needed.

\section{Acknowledgments}

This work was supported by Korea Research Founda- 
Table 1. Amino acid (AA) composition of SRSGH and SRSGH-II"

$(g / 100 \mathrm{~g} \mathrm{AA})$

\begin{tabular}{|c|c|c|c|c|c|}
\hline Amino acid & SRSGH & SRSGH-III & Amino acid & SRSGH & SRSGH-III \\
\hline Aspartic acid & 4.3 & 4.6 & Isoleucine & 0.8 & 0.8 \\
\hline Hydroxyproline & 8.8 & 11.8 & Leucine & 1.9 & 2.0 \\
\hline Threonine & 2.5 & - & Tyrosine & 0.4 & 0.5 \\
\hline Serine & 5.2 & 5.3 & Phenylalanine & 2.0 & 2.2 \\
\hline Glutamic acid & 9.1 & 9.4 & Hydroxylysine & 0.9 & 1.2 \\
\hline Proline & 10.8 & 11.7 & Lysine & 4.5 & 5.6 \\
\hline Glycine & 25.9 & 18.0 & Histidine & 0.9 & 1.2 \\
\hline Alanine & 9.1 & 9.4 & Arginine & 9.2 & 12.8 \\
\hline Valine & 2.1 & 2.1 & Total & 100.0 & 100.1 \\
\hline Methionine & 1.6 & 1.5 & & & \\
\hline
\end{tabular}

*SRSGH: rockfish skin gelatin hydrolysates sequentially hydrolyzed with Alcalase for $1.0 \mathrm{~h} /$ Flavourzyme for $2.0 \mathrm{~h}$. SRSGH-III: permeates from SRSGH through the $10 \mathrm{kDa}$ membrane but not permeated through the $5 \mathrm{kDa}$ membrane.

tion Grant funded by the Korean Government (KRF-2008521-F00044).

\section{References}

Byun HG and Kim SK. 2001. Purification and characterization of angiotensin I converting enzyme (ACE) inhibitory peptides from Alaska pollack (Theragra chalcogramma) skin. Process Biochem $36,1155-1162$.

Chang CY, Wu KC and Chiang SH. 2007. Antioxidant properties and protein composition of porcin haemoglobin hydrolysates. J Food Chem 100, 1537-1543.

Gbogouri GA, Linder M, Fanni J and Parmentier M. 2004. Influence of hydrolysis degree on the functional properties of salmon byproducts hydrolysates. J Food Sci 69, C615-C622.

Fishery Production Survey. 2011. Statistical Databases for Fisheries Production [Internet]. Korea National Statistical Office, Daejeon, KR, Accessed 26 May 2011, http://fs.fips.go.kr

Frega N, Mozzon M and Lercker G. 1999. Effects of free fatty acids on oxidative stability of vegetable oil. J Am Chem Soc 76, 325-329.

Hiramoto K, Jonkoh H, Sako K and Kikugawa K. 1993. DNA breaking activity of the carbon-centered radical generated from 2,2-azobis ( 2 amidinopropane) hydrochloride (AAPH). Free Radic Res Commun 19, 323-332.

Horiuchi M, Fujimura K, Terashima T and Iso T. 1982. Method for determination of angiotensin converting enzyme activity in blood and tissue by high-performance liquid chromatography. J Chromatogr 233, 123-130.

Jeon YJ, Byun HG and Kim SK. 2000. Improvement of functional properties of cod frame protein hydrolysates using ultrafiltration membranes. Process Biochem 35, 471-478.

Kim HJ, Yoon MS, Park KH, Shin JH, Heu MS and Kim JS. 2010. Processing optimization of gelatin from rockfish skin based on yield. Fish Aquat Sci 13, 1-11.
Kim HJ, Park KH, Shin JH, Lee JS, Heu MS, Lee DH and Kim JS. 2011. Antioxidant ACE inhibiting activities of the rockfish Sebastes hubbsi skin gelatin hydrolysates produced by sequential two-step enzymatic hydrolysis. Fish Aquat Sci 14, 1-10.

Kim JS and Park JW. 2004. Characterization of acid-soluble collagen from Pacific whiting surimi processing byproducts. J Food Sci 69, C637-C642.

Kim SK, Byun HG, Jeon YJ and Cho DJ. 1994. Functional properties of fish skin gelatin hydrolysate from a continuous two-stage membrane reactor. Agric Chem Biotechnol 37, 85-93.

Kim SK, Byun HG, Park PJ and Shahidi F. 2001a. Angiotensin I converting enzyme inhibitory peptides purified from bovine skin gelatin hydrolysate. J Agric Food Chem 49, 2992-2997.

Kim SK, Kim YT, Byun HG, Nam KS, Joo DS and Shahidi F. 2001b. Isolation and characterization of antioxidative peptides from gelatin hydrolysate of Alaska pollack skin. J Agric Food Chem 49, 1984-1989.

Kong CS, Kim JA, Qjan ZJ, Kim YA, Lee JI, Kim SK, Nam TJ and Seo Y. 2009. Protective effect of isorhamnetin 3-O- $\beta$-D-glucopyranoside from Salicornia herbacea against oxidation-induced cell damage. Food Chem Toxicol 47, 1914-1920.

Mendis E, Rajapakse N and Kim SK. 2005. Antioxidant properties of a radical-scavenging peptide purified from enzymatically prepared fish skin gelatin hydrolysate. J Agric Food Chem 53, 581-587.

Nanjo F, Goto K, Seto R, Suzuki M, Sakai M and Hara Y. 1996. Scavengingeffects of tea catechins and their derivatives on 1,1-diphenyl-2-picrylhydrazyl radical. Free Radic Biol Med 21, 895-902.

Rajapakse N, Mendis E, Jung WK, Je JY and Kim SK. 2005. Purification of a radical scavenging peptide from fermented mussel sauce and its antioxidant properties. Food Res Int 38, 175-182.

Rosen GM and Rauckman EJ. 1980. Spin trapping of superoxide and hydroxyl radicals. Meth Enzymol 105, 198-209.

Zhao BL, Li XJ, He R, Cheng SJ and Xin WJ. 1989. Scavenging effect of extracts of green tea and natural antioxidants on active oxygen radicals. Cell Biophys 14, 175-185. 